\title{
Impact of Pacific Decadal Oscillation on Frequency Asymmetry of El Niño and La Niña Events
}

\author{
Soon-Il AN* \\ Department of Atmospheric Sciences, Yonsei University, Seoul 03722, Korea
}

(Received 24 January 2018; revised 29 January 2018; accepted 31 January 2018)

\begin{abstract}
Citation: An, S.-I., 2018: Impact of Pacific Decadal Oscillation on frequency asymmetry of El Niño and La Niña events. $A d v$. Atmos. Sci., 35(5), 493-494, https://doi.org/10.1007/s00376-018-8024-7.
\end{abstract}

El Niño-Southern Oscillation (ENSO) is an abnormal sea surface warming or cooling phenomenon over the tropical Pacific, which also has severe global impact. Interestingly, ENSO characteristics are changing with climate change (e.g., Collins et al., 2010). Therefore, it is expected that ENSO can be modulated on the decadal time scale, particularly when the tropical climate background state is fluctuating strongly [i.e., Pacific Decadal Oscillation (PDO) and Interdecadal Pacific Oscillation (IPO)]. The main focus of previous ENSO research has been the amplitude, pattern, and El Niño-La Niña asymmetry modulation (e.g., An and Wang, 2000; Timmermann, 2003; Yeh et al., 2004; Choi et al., 2013; Ogata et al., 2013; Wittenberg et al., 2014; Okumura et al., 2017), whereas the dependency of ENSO occurrence on PDO has not been well studied.

A particular issue is whether PDO modulates the number of occurrences ["frequency" in Lin et al. (2018)] of El Niño and La Niña events; and, if so, what the underlying mechanism is. A new paper by Lin et al. (2018) (current issue) addresses the first question with a statistically strong case, for the first time in the literature, and provides a possible answer to the second question.

The sea surface temperature (SST) anomaly pattern for the positive PDO phase is usually identified as being warm in the tropical central to eastern Pacific and cold in the midlatitude northwestern Pacific, and vice versa for the negative PDO phase. Lin et al. (2018) show that El Niño events occur three times more frequently than La Niña events during the positive PDO phase, whereas the El Niño frequency is reduced by about a half of La Niña's occurrence during the negative PDO phase. This observational analysis is significant at the $99 \%$ confidence level based on the Monte Carlo test. A similar tendency is also evident in most CMIP5 models.

The underlying mechanism for the mean climate state modulating the ENSO frequency remains an open question. Lin et al. (2018) propose that the warm eastern tropical Pacific and anomalous westerlies over the central Pacific

\footnotetext{
* Corresponding author: Soon-Il AN

Email: sian@yonsei.ac.kr
}

associated with positive PDO may be more favorable for the occurrence of El Niño than La Niña. However, the underlying mechanism involved is not addressed. A strong positive correlation between ENSO amplitude and the mean SST over the eastern tropical Pacific (e.g., Choi et al., 2013; Ogata et al., 2013) implies that the stability of ENSO (i.e., its growth rate) is positively correlated with the PDO index. Actually, the linear stability of ENSO during the positive PDO phase is significantly larger than that during the negative PDO phase (An and Bong, 2016). Therefore, although there must be a greater frequency of ENSO events during the positive PDO phase, this linear dynamical approach cannot explain the ENSO frequency's asymmetry (Lin et al., 2018). Possible mechanisms for the ENSO frequency's asymmetry include nonlinear processes (An, 2009) or state-dependent weather noise (Jin et al., 2007), since nonlinearities will impact ENSO differently depending on its phase.

Importantly, the study by Lin et al. (2018) obliges the ENSO research community to focus on how PDO modulates the frequency of ENSO. Further studies have the potential to identify the decadal predictability of ENSO (e.g., Wittenberg et al., 2014), as well as to guide CGCM developers to improve its simulation.

Acknowledgements. This work was supported by the Basic Science Research Program of the National Research Foundation of Korea (Grant No. NRF-2017K1A3A7A03087790).

\section{REFERENCES}

An, S.-I., 2009: A review of interdecadal changes in the nonlinearity of the El Niño-Southern Oscillation. Theor. Appl. Climatol., 97, 29-40, https://doi.org/10.1007/s00704-008-0071-z.

An, S.-I., and B. Wang, 2000: Interdecadal change of the structure of the ENSO mode and its impact on the ENSO frequency. $J$. Climate, 13, 2044-2055, https://doi.org/10.1175/1520-0442 (2000)013<2044:ICOTSO>2.0.CO;2.

An, S.-I., and H. Bong, 2016: Inter-decadal change in El NiñoSouthern Oscillation examined with Bjerknes stability index analysis. Climate Dyn., 47, 967-979, https://doi.org/10.1007/ s00382-015-2883-8.

Choi, J., S.-I. An, S.-W. Yeh, and J.-Y. Yu, 2013: ENSO-like and ENSO-induced tropical Pacific decadal variability in 
CGCMs. J. Climate, 26, 1485-1501, https://doi.org/10.1175/ JCLI-D-12-00118.1.

Collins, M., and Coauthors, 2010: The impact of global warming on the tropical Pacific Ocean and El Niño. Nature Geoscience, 3, 391-397, https://doi.org/10.1038/ngeo868.

Jin, F.-F., L. Lin, A. Timmermann, and J. Zhao, 2007: Ensemblemean dynamics of the ENSO recharge oscillator under state-dependent stochastic forcing. Geophys. Res. Lett., 34, L03807, https://doi.org/10.1029/2006GL027372.

Lin, R. P., F. Zheng, and X. Dong, 2018: ENSO frequency asymmetry and the Pacific Decadal Oscillation in observations and 19 CMIP5 models. Adv. Atmos. Sci., 35(5), https://doi.org/ 10.1007/s00376-017-7133-z.

Ogata, T., S.-P. Xie, A. Wittenberg, and D.-Z. Sun, 2013: Interdecadal amplitude modulation of El Niño-Southern Oscillation and its impact on tropical Pacific decadal variability. $J$. Climate, 26, 7280-7297, https://doi.org/10.1175/JCLI-D-12-
00415.1.

Okumura, Y. M., T. Y. Sun, and X. Wu, 2017: Asymmetric modulation of El Niño and La Niña and the linkage to tropical Pacific decadal variability. J. Climate, 30, 4705-4733, https://doi.org/10.1175/JCLI-D-16-0680.1.

Timmermann, A., 2003: Decadal ENSO amplitude modulations: A nonlinear paradigm. Global and Planetary Change, 37, 135-156, https://doi.org/10.1016/S0921-8181(02)00194-7.

Wittenberg, A. T., A. Rosati, T. L. Delworth, G. A. Vecchi, and F. R. Zeng, 2014: ENSO modulation: Is it decadally predictable? J. Climate, 27, 2667-2681, https://doi.org/10.1175/ JCLI-D-13-00577.1.

Yeh, S.-W., J.-G. Jhun, I.-S. Kang, and B. P. Kirtman, 2004: The decadal ENSO variability in a hybrid coupled model. $J$. Climate, 17, 1225-1238, https://doi.org/10.1175/1520-0442 (2004)017<1225:TDEVIA > 2.0.CO;2. 